\title{
Trends in natural product research: PSE young scientists' meeting Lille 2017
}

\author{
Natural products in health, agro-food and cosmetics
}

\author{
Céline Rivière $\cdot$ Jean-Louis Hilbert
}
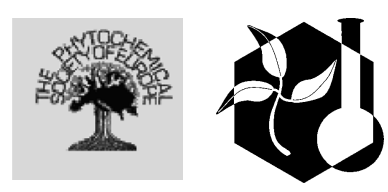

Published online: 27 August 2018

(C) Springer Nature B.V. 2018

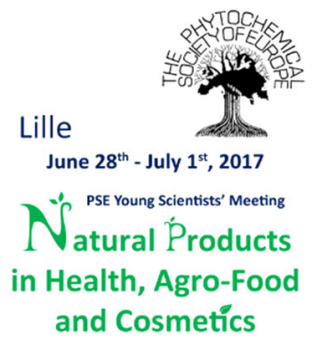

In recent years, there has been renewed interest in plant extracts and natural products to discover safer and lower-risk products from a human health perspective, and to find solutions to environmental issues. It was in this context that the Phytochemical Society of Europe (PSE) and the Charles Viollette Institute (ICV) organized the PSE Young Scientists' Meeting (YSM) from Wednesday June 28th to Saturday July 1st, 2017 at Polytech Lille (Villeneuve d'Ascq, France). This meeting, entitled "Natural Products in Health, AgroFood and Cosmetics", was an opportunity for all researchers in phytochemistry and plant biology, young or experienced, working in different fields of application to present their work in the form of oral communications or posters. The first day of the meeting focused on the development of new

C. Rivière $(\square)$ · J.-L. Hilbert

Charles Viollette Institute, University of Lille, Lille,

France

e-mail: celine.riviere@univ-lille.fr methodologies, particularly related to metabolomics, genomics and transcriptomics. The second day highlighted recent research on natural antimicrobial and anti-inflammatory agents. The last day put the emphasis on chemopreventive and anticancer natural products, traditional medicines and bioactivities, and new methods in phytochemical analysis.

This international meeting brought together 170 attendees from 28 countries. 14 plenary lectures by renowned researchers in the field have introduced 12 sessions. The Scientific Committee selected 4 other lectures by confirmed researchers, 26 short lectures by young scientists and 85 posters on fairly broad topics about natural products: purification and structural identification; hemi-synthesis and synthesis; biological activities; bioavailability; metabolomics; plant biotechnology; method validation; functional genomics; ethnopharmacology; chemotaxonomy. More than 100 presentations were given at the meeting, expanding and diversifying the purview of the abstract volume. $^{1}$

\footnotetext{
$\overline{1 \text { Abstracts of }} 132$ presentations given at the meeting were published in English in July 2017 as C. Rivière, Ed 2017. Trends in Natural Product Research-PSE Young Scientists' Meeting Lille 2017. Natural Products in Health, Agro-food and Cosmetics: Abstracts of the Phytochemical Society of Europe. Phytochemical Society of Europe, Leicester. 211 pp. ISBN-13 978-09565472-6-2.
} 
This special issue of 11 reviews is drawn from some of the meeting's featured lectures. They do not cover all the relevant topics of the meeting but illustrate some of the ongoing research on natural products with applications in different sectors, including health, agro-food and cosmetics.

The key theme of the first day of the meeting was the development of "-omics" approaches for nutrition, food science, agriculture and human health. In this context, de Falco and Lanzotti (2018) rightly pointed out in their review the benefits and limitations of metabolomics using NMR and mass spectrometry in the study of the composition of species from the genus Salvia.

In this issue, several authors have highlighted the biological potential of plant-derived natural products of interest in human health. These compounds combine medicinal, nutritional and/or organoleptic properties.

Stilbenoids are a family of phenolic compounds known for the complexity of their structure and for their biological activities. Stilbenoids include the extensively studied monomeric stilbene $E$-resveratrol, a key polyphenol, which might partly explain the "French paradox", even though the latter is widely debated and controversial. Şöhretoğlu et al. (2018) reviewed the botanical sources, pharmacology, biosynthesis, biotechnological production and bioactivities of polydatin, a resveratrol glucoside. They have highlighted the therapeutic potential of this molecule, especially against degenerative diseases. They pointed out the bioavailability of this compound as a limiting factor in clinical applications. Interestingly, El Khawand et al. (2018) focused their review on the recent data concerning the bioavailability, pharmacokinetics and metabolism of dietary stilbenes, including monomers and oligomers. The authors showed the importance of a better knowledge of the pharmacological activity of the metabolites formed for a therapeutic use of these natural products in humans.

Morus species are known to produce phenolic compounds including stilbenes and prenylflavonoids with biological potential. Although M. nigra does not have the same history as feed for silkworms in commercial silk production, its fruits are edible, like M. alba, and are sometimes confused with the fruits of black-fruited individuals in this species. Zoofischan et al. (2018) outlined the antioxidant activities of phenolic compounds isolated from M. nigra, with an emphasis on in vivo evidence. They also highlighted the antitumor properties of morusin, a major prenylflavonoid found in the bark of M. nigra root.

Hop (Humulus lupulus), a well-known beer ingredient, is enjoying renewed interest due to the fashion for very hoppy beers. This plant is recognized for its bioactive prenylated chalcones and acylphloroglucinols that have sedative, antimicrobial and oestrogenic properties, among others. Bocquet et al. (2018) reviewed the phytochemistry, biological activities and plant biotechnology of this species.

The Mediterranean tree Olea europaea, and in particular its fruits, have historically been recognized for their nutritional value. Guo et al. (2017) reviewed the chemical composition and nutritional function of olive. They put the emphasis on the interest of phenolic compounds.

Diabetes mellitus and bacterial resistance are two major public health issues at the moment. In this context, Teoh and Das (2018) discussed the interest of some plant-derived natural products in the treatment of diabetes mellitus. Catteau et al. (2018) reviewed the antibacterial potential of 78 pentacyclic triterpenoids belonging to the ursane, oleanane and lupane groups against Staphylococcus aureus. So far, eight of these metabolites have been studied in combination with antibiotics. Some of these studies demonstrated encouraging interactions to be investigated further.

Lichens, also called lichenized fungi or lichenizing fungi, are a great source of bioactive natural products. These composite organisms result from a symbiosis between at least one heterotrophic fungus, representing $90 \%$ of the total, and chlorophyll microscopic cells (green alga or cyanobacterium carbon autotrophic). Ismed et al. (2018) summarized the phytochemistry and biological activities of the lichen genus Stereocaulon, with a focus on nine species. The authors also highlighted the importance of morphological aspects in discriminating between similarly shaped species, providing some personal data.

Natural products and plant extracts are also of interest to the cosmetic companies at a time when the use of synthetic excipients is rather controversial. Traversier et al. (2018) reviewed recent trends in the extraction, separation, analysis and main applications of polar lipids, which, due to their amphiphilic properties and their biological profile, may be particularly useful to the cosmetic industry. 
Access to genetic resources and benefit sharing have been strengthened with the Nagoya Protocol. David (2018) summarized some historical elements and fundamentals of legislation. He also examined new regulations on biological resources and then provided practical advices and recommendations of a great interest for industrial and academic users.

We are grateful to the many people who helped us to organize the meeting. The local French organizing committee board was composed by Céline Rivière (chairman), Jean-Louis Hilbert (co-chairman), Thierry Hennebelle, Sevser Sahpaz, Simon Bordage, Françoise Coucheney, David Gagneul, Philippe Hance, Rozenn Ravallec, Vincent Roumy, Ali Siah, Laetitia Bocquet, Sophie Lefèbvre and Jennifer Samaillie. We also thank all ICV Ph.D. students who helped us successfully convene the meeting. The international Scientific Committee was comprised of representatives from several countries: Randoph Arroo (UK), Pinarosa Avato (Italy), Franz Bucar (Austria), Pierre Champy (France), Eldra Delannay (France), Simon Gibbons (UK), Virginia Lanzotti (Italy), Francisco A Macias (Spain), Stéphanie Krisa (France), Joëlle Quetin-Leclercq (Belgium), Céline Rivière (France), Satyajit Sarker (UK), Véronique Seidel (UK), Didem Şöhretoğlu (Turkey), Miroslav Strnad (Czech Republic), Rob Verpoorte (The Netherlands) and Jianbo Xiao (China). The success of the meeting depended on the enthusiasm and support from the management of Polytech Lille, who welcomed us to their premises.

We would like to thank all our sponsors, without whom this meeting would never have taken place: institutional support, notably from the Hauts-de-France region, but also University of Lille 2, University of Lille 1, Polytech Lille, PSE, ICV, the city of Lille; and industrial sponsors: Extrasynthèse, RIC, Yves Rocher, Gilson, Shimadzu, Thieme, PhytoLab, Florimond Desprez, Leroux, Macherey-Nagel. Many thanks to Sophie Lefèbvre from Perspectives and Organization, who helped us make this conference a success.

During the meeting, some bursaries and prizes were awarded to students, including 4 PSE travel bursaries (Ankit Saneja; Divya Arora; Kristof Cank; Lucy Owen), one Jeffrey Harborne prize and 2 Wiley prizes. Two $\mathrm{Ph}$.D. students received awards for their oral presentation: Ivana Turek (Jeffrey Harborne prize) and Alexander E. Fox Ramos (Wiley prize). Lucas Apolinário Chibli received a Wiley prize for the best poster presentation. In the PSE/Pierre Fabre Innovation Awards 2017, the winners were Prof. Francesco Epifano (Central Nervous System), Prof. Srijit Das (Dermatology) and Florent Olivon (Oncology).

We also greatly appreciate the work of the reviewers who have provided their opinions with much enthusiasm. Finally, we warmly acknowledge the editors of Phytochemistry Reviews, in particular Rob Verpoorte, for giving us the opportunity to produce this special issue.

\section{References}

Bocquet L, Sahpaz S, Hilbert JL, Rambaud C, Rivière C (2018) Humulus lupulus L., a very popular beer ingredient and medicinal plant: overview of its phytochemistry, its bioactivity, and its biotechnology? Phytochem Rev. https:// doi.org/10.1007/s11101-018-9584-y

Catteau L, Zhu L, Van Bambeke F, Quetin-Leclercq J (2018) Natural and hemi-synthetic pentacyclic triterpenes as antimicrobials and resistance modifying agents against Staphylococcus aureus: a review. Phytochem Rev. https:// doi.org/10.1007/s11101-018-9564-2

David B (2018) New regulations for accessing plant biodiversity samples, what is ABS? Phytochem Rev. https://doi.org/10. 1007/s11101-018-9573-1

de Falco B, Lanzotti V (2018) NMR spectroscopy and mass spectrometry in metabolomics analysis of Salvia. Phytochem Rev. https://doi.org/10.1007/s11101-018-9550-8

El Khawand T, Courtois A, Valls J, Richard T, Krisa S (2018) A review of dietary stilbenes: sources and bioavailability. Phytochem Rev. https://doi.org/10.1007/s11101-018-9578-9

Guo Z, Jia X, Zheng Z, Lu X, Zheng Y, Zheng B, Xiao J (2017) Chemical composition and nutritional function of olive (Olea europaea L.): a review. Phytochem Rev. https://doi. org/10.1007/s11101-017-9526-0

Ismed F, Lohézic-Le Dévéhat F, Guiller A, Corlay N, Bakhtiar A, Boustie J (2018) Phytochemical review of the lichen genus Stereocaulon (Fam. Stereocaulaceae) and related pharmacological activities highlighted by a focus on nine species. Phytochem Rev. https://doi.org/10.1007/s11101018-9576-y

Şöhretoğlu D, Baran MY, Arroo R, Kuruüzüm-Uz A (2018) Recent advances in chemistry, therapeutic properties and sources of polydatin. Phytochem Rev. https://doi.org/10. 1007/s11101-018-9574-0

Teoh SL, Das S (2018) Phytochemicals and their effective role in the treatment of diabetes mellitus: a short review. Phytochem Rev. https://doi.org/10.1007/s11101-018-9575-z

Traversier M, Gaslondes T, Milesi S, Michel S, Delannay E (2018) Polar lipids in cosmetics: recent trends in extraction, separation, analysis and main applications. Phytochem Rev. https://doi.org/10.1007/s11101-018-9588-7

Zoofishan Z, Hohmann J, Hunyadi A (2018) Phenolic antioxidants of Morus nigra roots, and antitumor potential of morusin. Phytochem Rev. https://doi.org/10.1007/s11101018-9565-1 